\title{
Effectiveness of Three Different Application Times of 17\% EDTA and 7\% Maleic Acid Irrigation Agents on the Removal of Debris and Smear Layer: A Scanning Electron Microscope Study
}

\author{
Sadullah Kaya ${ }^{1}$, Özkan Adıgüzel ${ }^{1}$, İbrahim Uysal ${ }^{2}$, Selengül Ganidağlı Ayaz ${ }^{2}$ \\ ${ }^{1}$ Assistant Professor, Dicle University, Faculty of Dentistry, Department of Endodontics, Diyarbakır, TURKEY \\ ${ }^{2}$ Research Assistant, Dicle University, Faculty of Dentistry, Department of Endodontics, Diyarbakır, TURKEY
}

\section{Key Words}

EDTA, maleic acid, smear layer, debris.

\section{Correspondence:}

Sadullah KAYA

Dicle University,

Faculty of Dentistry,

Department of Endodontics,

21280, Diyarbakir, TURKEY.

e-mail: sadullahkaya@hotmail.com

\begin{abstract}
Aim: This study compared smear-layer and debris removal using with three different application times of 17\% EDTA and 7\% maleic acid irrigation agents.

Methodology: Fifty-two maxillary and mandibular single-rooted teeth were divided randomly into seven groups $(n=8$ each, control group $n=4)$. Three groups received $17 \%$ EDTA and three received maleic acid $(1,5,10 \mathrm{~min})$. Canals were prepared using nickeltitanium rotary files. Smear-layer and debris removal were evaluated in the coronal, middle, and apical thirds of the teeth using scanning electron microscopy, and results were analyzed compared using Mann-Whitney U tests.

Results: Maleic acid removed the smear layer (coronal and middle: $p<0.01$; apical: $p<0.05$ ) and debris (all $p<0.05$ ) more effectively than EDTA in terms of 1 min application period. Effectiveness did not differ significantly with 10-min applications.

Conclusions: Final irrigation with $7 \%$ maleic acid is more efficient than $17 \%$ EDTA in the removal of smear layer and debris from the coronal, middle and apical third of the root canal system in application within $1 \mathrm{~min}$.
\end{abstract}

(Int Dent Res 2011;2:48-54)

\section{Introduction}

One of the major advantages of root canal treatment is the achievement of clean canals before filling (1). Micro-organisms can be controlled in infected root canals through adequate biomechanical expansion of the canal and effective canal irrigation. It is also extremely important that organic and inorganic residues and debris are removed from canals effectively $(1,2)$.
Microscopic evaluation has shown that root canals vary considering the irregular and complex secondary canals. Carious and traumatic lesions may also change the character of the tooth pulp and allow the invasion of pathogens and toxins into dentin canals. Such invasions devitalise the pulp, negatively impacting the ability to treat the canal successfully (3). The success of root canal treatment depends on good shaping, removal of infected tissues, and proper filling of the canal. Previous 
studies have shown that the instruments used in canal expansion and shaping generate a smear layer that covers the dentine walls (4). The smear layer, which contains bacterial cells, impedes proper canal filling and prevents the diffusion of dentine canals (1). It has been shown that the smear layer itself may be infected and may protect the bacteria within the root canal dentinal tubules (1). Various chelating agents like citric acid, EDTA, and a mixture of tetracycline isomer (doxycycline), an acid (citric acid) and a detergent (Tween 80 ) have been used for the removal of the smear layer in root canal walls $(5,6)$. The use of a combination of sodium hypochlorite $(\mathrm{NaOCl})$ and the chelating agent EDTA has been recommended for effective removal of the smear layer (6). Particularly some researchers have suggested the use of $17 \%$ ethylenediaminetetraacetic acid (EDTA) and 5\% sodium hypochloride $(\mathrm{NaOCl})$ for the effective cleaning of root canals $(7,8)$. However, some researchers have also been reported following the combined use of these materials, such as the erosion of dentine walls (911).

The strong demineralising effect of EDTA can cause enlargement of dentine tubules, softening of dentine, and denaturing of collagen fibres. These effects can impede the adaptation of canal filling materials to dentine walls (12). Bystrom et al. (13) determined that $5 \% \mathrm{NaOCl}$ with $15 \%$ EDTA removed bacteria and the smear layer more effectively than $5 \% \mathrm{NaOCl}$ alone. Although $\mathrm{NaOCl}$ removes organic components effectively, it has been reported to have no impact on the removal of inorganic components. It should thus be used in combination with chelating agents to ensure proper root canal debridement $(6,7,14)$.

Maleic acid is a mild organic acid used as an acid conditioner in adhesive dentistry (15). It has been found to acquire the smear layer-removing high quality when used as an acid etchant in restorative dentistry $(15,16)$. So far, there was only a few study published evaluating the different concentrations $(5 \%, 7 \%, 10 \%$, or $15 \%)$ of maleic acid in the removal of the smear layer from the root canal dentin $(17,18)$.

The purpose of this study was to conduct a scanning electron microscopic (SEM) analysis comparing the effectiveness of $1-, 5-$, and 10-min applications of $\mathrm{NaOCl} / 17 \%$ EDTA and $\mathrm{NaOCl} / 7 \%$ maleic acid in the removal of the smear layer and debris in the coronal, middle, and apical thirds of root canals.

\section{Materials and Methods}

The study sample consisted of 52 extracted maxillary and mandibular single-rooted non-carious teeth, chosed randomly from male and female patients between the ages of 20 and 45 years. The teeth were soaked in $0.5 \%$ chloramine-T solution for 1 week to prevent bacterial growth. Before preparation, all teeth were cleaned with distilled water. The crowns were removed at the cementodentinal junction with a diamond disk (KG Sorensen, Barueri, SP, Brazil). Working lengths were defined 1 $\mathrm{mm}$ short of the apices with a \#10 K-file. Using the crown-down technique, the root canals were prepared to size $30(F 3,0.04)$ with ProTaper nickeltitanium (Ni-Ti) rotary instruments (DentsplyMaillefer, Ballaigues, Switzerland). Each instrument was replaced after it had been used on two teeth. An irrigation agent ( $5 \mathrm{~mL} 2.5 \% \mathrm{NaOCl}$ solution) was applied with a 27-gauge needle during each rasping procedure. After instrumentation and irrigation, the teeth were randomly divided into seven groups for the final irrigation regime. All of the solutions used were prepared freshly. The groups received the following treatments:

Group A $(n=8): 5 \mathrm{~mL}$ 17\% EDTA (Roth International Ltd., Chicago, IL, USA) for $1 \mathrm{~min}$, followed by $5 \mathrm{~mL}$ distilled water;

Group B $(\mathrm{n}=8): 5 \mathrm{~mL}$ maleic acid (KMC Pharmacy, Karnataka, India) for 1 min, followed by $5 \mathrm{~mL}$ distilled water;

Group C ( $\mathrm{n}=8)$ : $5 \mathrm{~mL} 17 \%$ EDTA for $5 \mathrm{~min}$, followed by $5 \mathrm{~mL}$ distilled water;

Group $D(n=8): 5 \mathrm{~mL}$ maleic acid for $5 \mathrm{~min}$, followed by $5 \mathrm{~mL}$ distilled water;

Group E $(\mathrm{n}=8): 5 \mathrm{~mL} 17 \%$ EDTA for $10 \mathrm{~min}$, followed by $5 \mathrm{~mL}$ distilled water;

Group $F(n=8): 5 \mathrm{~mL}$ maleic acid for $10 \mathrm{~min}$, followed by $5 \mathrm{~mL}$ distilled water;

Group $\mathrm{G}$ (control, $\mathrm{n}=4$ ): $5 \mathrm{~mL} 2.5 \% \mathrm{NaOCl}$, followed by $5 \mathrm{~mL}$ distilled water.

Thereafter, all teeth were dried with paper points.

\section{SEM Evaluation}

For SEM examination, the buccal and lingual surfaces of all roots were grooved longitudinally with a fissure diamond bur in a high-speed handpiece (diameter $125 \mathrm{~mm} \times 0.35 \mathrm{~mm} \times 12.7 \mathrm{~mm}$ ), under copious water irrigation, avoiding penetration of the root canals. The specimens were then placed in a desiccator for at least $48 \mathrm{~h}$. The samples were bisected and both halves were mounted in specimen holders. They were then placed in a vacuum chamber and coated with a $25-\mu \mathrm{m}$ thick goldpalladium layer for SEM (JEOL T330; JSM, Tokyo, Japan) analysis. After the samples were coated with $10 \mu \mathrm{m}$ of gold, SEM photomicrographs were taken at 2500x magnification. The coronal, middle, and apical thirds of all samples were evaluated. 


\section{Image analysis}

Two operators evaluated the SEM images using a double-blind method and the scoring system of Ahmad et al. (19) The debris and smear-layer quantities were each given a score between 0 and 3 , as follows:

\section{Debris scores:}

$0=$ no superficial debris on the dentine wall;

$1=$ minimal debris;

2 = moderate debris;

$3=$ heavy amounts of debris.

\section{Smear scores:}

$0=$ no smear on the dentine wall, all tubules opened;

1 = light smear, $>50 \%$ of tubules opened; opened;

$2=$ moderate smear, $<50 \%$ of tubules

$3=$ heavy smear, outlines of tubules obliterated.
Intra- and interexaminer reliability for the SEM assessment was verified by the Kappa test. Mean debris and smear-layer scores were calculated for each tooth and group, and the groups were compared using the Mann-Whitney $U$ test at a significance of .05 . The results obtained at each evaluation level within each group were analysed using Friedman's nonparametric two-way analysis of variance (ANOVA). Statistical data were evaluated using the SPSS software (ver. 10.0; SPSS Inc., Chicago, IL, USA).

\section{Results}

Table 1 presents the results of different application time of EDTA and maleic acid solutions on removal of the smear layer and debris in the coronal, middle, and apical thirds of the root canals.

TABLE 1. $P$ values for smear layer removal among groups $A$ to $F$

\begin{tabular}{|c|c|ll|}
\hline Canal Level & Time & \multicolumn{1}{c|}{ Group Comparison } & $p$ Value \\
\hline Coronal & $1 \mathrm{~min}$ & Group B was cleaner than group A & $\mathrm{p}<0.01$ \\
\hline Coronal & $5 \mathrm{~min}$ & No significant difference between groups C and D & $\mathrm{p}=0.264$ \\
\hline Coronal & $10 \mathrm{~min}$ & No significant difference between groups E and F & $\mathrm{p}=0.293$ \\
\hline Middle & $1 \mathrm{~min}$ & Group B was cleaner than group A & $\mathrm{p}<0.01$ \\
\hline Middle & $5 \mathrm{~min}$ & No significant difference between groups C and D & $\mathrm{p}=0.175$ \\
\hline Middle & $10 \mathrm{~min}$ & No significant difference between groups E and F & $\mathrm{p}=0.530$ \\
\hline Apical & $1 \mathrm{~min}$ & Group B was cleaner than group A & $\mathrm{p}<0.05$ \\
\hline Apical & $5 \mathrm{~min}$ & Group D was cleaner than group C & $\mathrm{p}<0.01$ \\
\hline Apical & $10 \mathrm{~min}$ & No significant difference between groups E and F & $\mathrm{p}=0.165$ \\
\hline
\end{tabular}

TABLE 2. $P$ values for debris removal among groups $A$ to $F$

\begin{tabular}{|c|c|c|c|}
\hline Canal Level & Time & Group Comparison & p Value \\
\hline Coronal & $1 \mathrm{~min}$ & Group B was cleaner than group A & $p<0.05$ \\
\hline Coronal & $5 \mathrm{~min}$ & No significant difference between groups $C$ and $D$ & $\mathrm{p}=0.589$ \\
\hline Coronal & $10 \mathrm{~min}$ & No significant difference between groups $\mathrm{E}$ and $\mathrm{F}$ & $\mathrm{p}=0.424$ \\
\hline Middle & $1 \mathrm{~min}$ & Group B was cleaner than group A & $p<0.05$ \\
\hline Middle & $5 \mathrm{~min}$ & No significant difference between groups $\mathrm{C}$ and $\mathrm{D}$ & $\mathrm{p}=0.114$ \\
\hline Middle & $10 \mathrm{~min}$ & No significant difference between groups $\mathrm{E}$ and $\mathrm{F}$ & $p=0.575$ \\
\hline Apical & $1 \mathrm{~min}$ & Group B was cleaner than group A & $p<0.05$ \\
\hline Apical & $5 \mathrm{~min}$ & Group D was cleaner than group C & $p<0.05$ \\
\hline Apical & $10 \mathrm{~min}$ & No significant difference between groups $\mathrm{E}$ and $\mathrm{F}$ & $\mathrm{p}=0.069$ \\
\hline
\end{tabular}




\section{Smear layer removal}

Kappa test results, with a significance set at .05 and .01 (1 and $5 \mathrm{~min}$.), showed good intra- and interexaminer agreement. After 1-min applications, the amount of smear layer removal differed significantly in the coronal, middle (both $p<0.01$ ), and apical $(p<0.05)$ thirds of the root canals. After 5-min applications, smear layer removal differed significantly only in the apical third $(p<0.01)$. No significant difference was observed after 10-min applications. maleic acid removed the smear layer more effectively than EDTA (Fig. 1), especially with an application of short duration (1 $\mathrm{min})$.
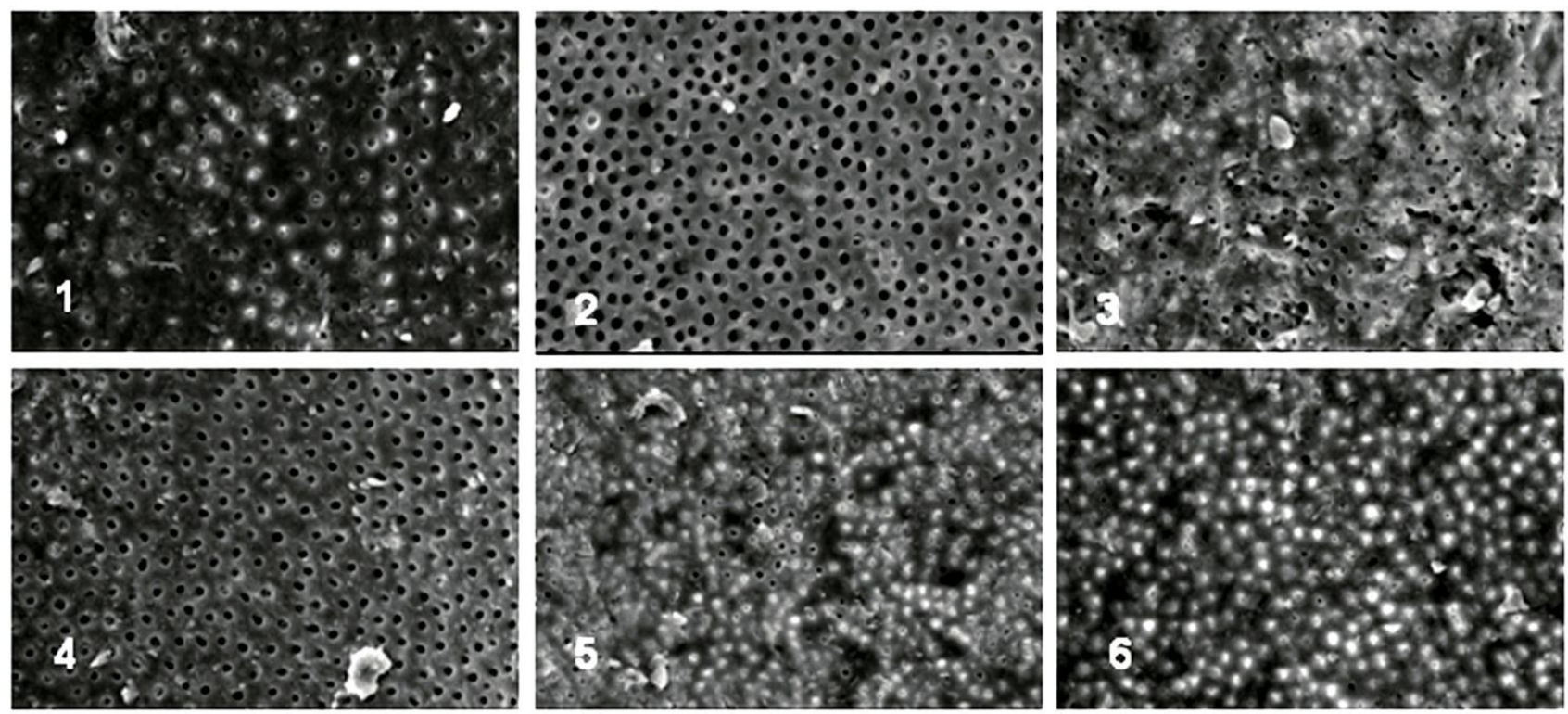

Figure 1. Scanning electron microscopic images of root canal walls (2500x). (1) Group A, EDTA (1 min), coronal third (smear score 2, debris score 1); (2) Group B, maleic acid (1 min), coronal third (smear score 0, debris score 0); (3) Group C, EDTA (5 min), middle third (smear score 2, debris score 1); (4) Group D, maleic acid (5 min), middle third (smear score 0, debris score 0); (5) Group E, EDTA (10 min), apical third (smear score 3, debris score 2); (6) Group F, maleic acid (10 min), apical third (smear score 3, debris score 2).

\section{Debris removal}

Kappa test results, with a significance set at .05 (1 and 5 min.), showed good intra- and interexaminer agreement. After 1-min applications, the amount of debris removal differed significantly in the coronal, middle, and apical (all p < 0.05) thirds of the root canals. After 5-min applications, debris removal differed significantly only in the apical third $(p<0.05)$. No significant difference was observed after 10-min applications. maleic acid removed debris more effectively than EDTA (Fig. 1), especially with an application of short duration (1 $\min )$.

The control group demonstrated that $\mathrm{NaOCl}$ was ineffective for the removal of the smear layer and debris (Fig. 2).

Table 2 presents the results of intra-group evaluations, conducted using Friedman's ANOVA. In the middle third of the root canal, EDTA removal of the smear layer differed significantly with application length $(p<0.05)$. No significant difference was observed for the removal of smear layer and debris in the coronal and apical thirds with different lengths of EDTA application. Maleic acid intra-group comparison revealed no significant difference in the removal of smear layer and debris among application lengths and root canal portions.

\section{Discussion}

The purpose of this study was to evaluate the smear-layer and debris removal effects of three application lengths of $7 \%$ maleic acid and $17 \%$ EDTA during final irrigation, following initial irrigation with $2.5 \% \mathrm{NaOCl}$. 


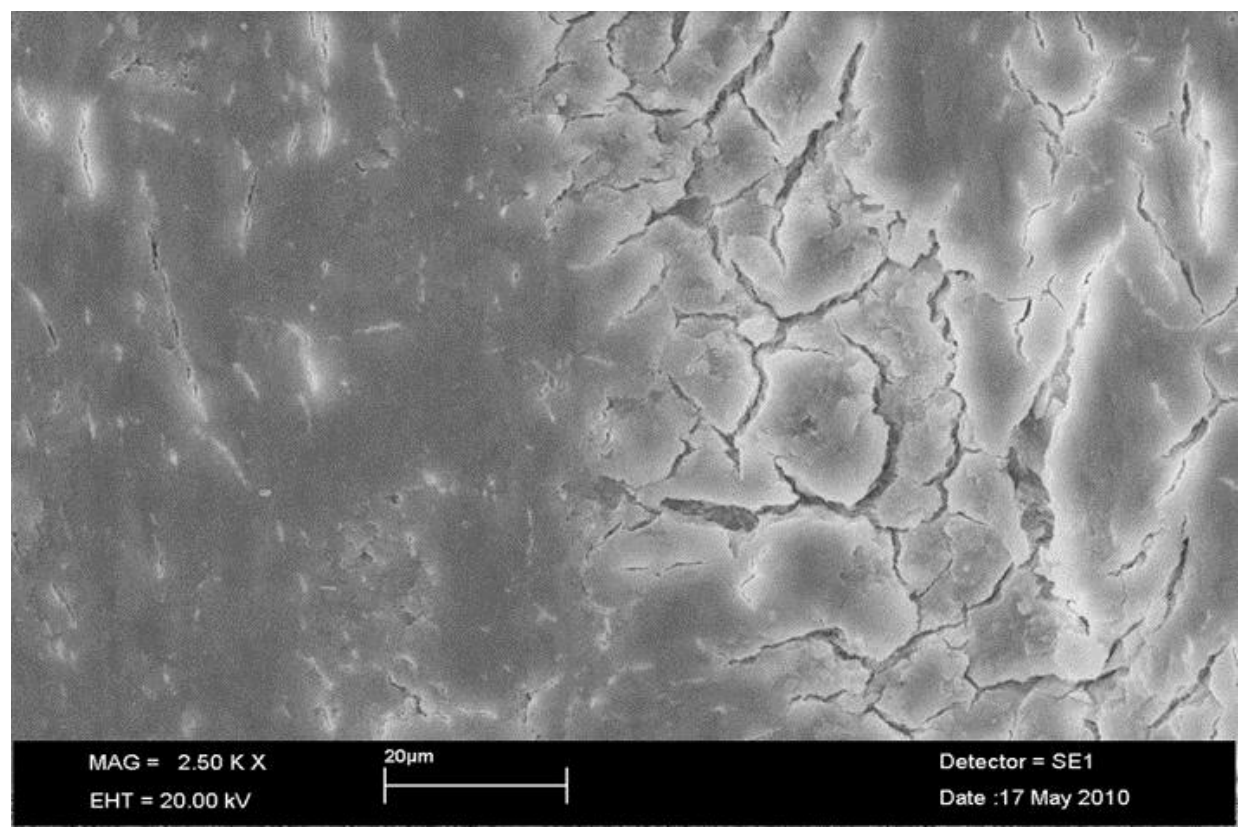

Figure 2. Scanning electron microscopic images of root canal walls (2500x). Control group, $\mathrm{NaOCl}$ (smear score 3, debris score 3).

Many researchers have demonstrated that debris and the smear layer occur during canal expansion and shaping as a result of the mechanical expansion applied to root canals $(20,21)$. The debris and smear layer provide a favourable environment for the reproduction of microorganisms and bacteria, and may distort the adhesion of root canal fillings to the canal wall. This distortion may, in turn, lead to apical leakage, preventing the expansion of intracanal medicaments into dentine canals $(1,2)$. Components that will negatively impact the success of canal treatment must be removed from root canals; several tissue solvents and removal solutions are used for this purpose during endodontic treatment. Irrigation solutions must dissolve organic and inorganic components and remove the smear layer. The widely used $\mathrm{NaOCl}$ irrigation agent has superior tissue-solvent characteristics, but is insufficient for the removal of inorganic components. Researchers have thus sought other agents, such as $\operatorname{EDTA}(11), \operatorname{MTAD}(6)$, maleic acid $(17,18)$, and citric acid (7) chelating agents. These agents remove inorganic components, debris, and the smear layer effectively when used in combination with $\mathrm{NaOCl}$ $(3,11,22)$.

EDTA is a widely used chelating agent in endodontic treatments (23). Many studies have reported that the combined use of EDTA and $\mathrm{NaOCl}$ removes the smear layer effectively; the most effective final irrigation has been reported to be 10 $\mathrm{mL} 17 \%$ EDTA, followed by $10 \mathrm{~mL} 5.25 \% \mathrm{NaOCl}$ $(7,8,24)$.
O'Connell et al. (25) reported that the combined use of EDTA and $5.25 \% \mathrm{NaOCl}$ for canal irrigation removed the smear layer effectively in the middle and coronal thirds of the root canal, but achieved only inefficient removal in the apical third. They suggested that this shortcoming was due to insufficient irrigant volume or insufficient penetration into the apical third of the canal. The results of the present study were consistent with their findings.

Çalt and Serper (9) compared 1-min and 10min applications of $17 \%$ EDTA to root canals as an irrigation agent. The smear layer was removed effectively with a 1-min application, whereas periand intra-tubular erosion occurred during a 10 -min application. Gettleman et al. (26) showed that a contact time of 3 min with 17\% EDTA was effective for smear layer removal.

Ballal et al. (18) reported that $7 \%$ maleic acid followed by $2.5 \%$ sodium hypochlorite had a better smear layer removal ability than $17 \%$ EDTA followed by $2.5 \%$ sodium hypochlorite in the apical third of the root canal system during the application for 1 min. In the middle and coronal third, both EDTA and maleic acid were equally effective without any statistical difference between them. The results of our study for 5 min. (smear layer and debris) are consistent with their findings. However, application for $10 \mathrm{~min}$. (all regions) showed no significant difference between EDTA and maleic acid groups. Furthermore, in the present study maleic acid had a better smear layer and debris removal ability than $17 \%$ EDTA in the coronal, middle, and apical thirds of the root canal system during the application for 1 $\min$. 
EDTA did not remove smear layer and debris effectively when compared with maleic acid in root canal walls. This maybe due to the increased surface tension of $17 \%$ EDTA $(0.0783 \mathrm{~N} / \mathrm{m})$ when compared with that of $7 \%$ maleic acid $(0.06345 \mathrm{~N} / \mathrm{m})(18)$. Since EDTA is a chelating agent, it is effective at a neutral $\mathrm{pH}$ and it is independent on a high hydrogen ion concentration to induce decalcification. Calcium released from dentin decreases $\mathrm{pH}$ with the resulting hydrogen. With a positive correlation the efficacy of EDTA decreases over time because of the decrease in $\mathrm{pH}$ (2). Since maleic acid is highly acidic, it demineralises within a shorter period of time. However, EDTA requires an application time of not less than 15 minutes for optimal results (27). EDTA solution reduces the mineral and noncollagenous proteins of dentin (2). As Hülsmann et al. (2) reported that the content of noncollagenous proteins component decreased in the apical third of the root canal system, the degree of decalcification of EDTA in this part was low. Also, Çalt et al. (9) and Niu et al. (10) reported that when was EDTA used for more than 1 minute it had caused erosion of dentinal tubules. Kuah et al. (28) compared the effectiveness of 1-min and 3-min ultrasonic applications of EDTA on smear layer removal, finding no significant difference. They reported that a 1-min application removed the smear layer in the tested region. Jiang et al. (29) applied irrigation agents with sonic tools and evaluated debris removal in root canal thirds. They found that this application improved the activation of irrigants and removed debris effectively. Mello et al. (30) reported that a 3-min application of $3 \mathrm{~mL} 17 \%$ EDTA as a final solution effectively removed the smear layer in root canals. $\mathrm{NaOCl}$, which is used as an irrigant in the control group, was found to have no effect on the smear layer and debris removal.

\section{Conclusion}

Within the limitations of this study, a 1-min application of $7 \%$ maleic acid during final irrigation removed the smear layer and debris more effectively than a 1-min application of $17 \%$ EDTA in the coronal, middle, and apical thirds of root canals.

\section{Acknowledgments}

\author{
The authors deny any conflicts of interest \\ related to this study.
}

\section{References}

1. Torabinejad $M$, Handysides $R$, Khademi $A A$, Bakland LK. Clinical implications of the smear layer in endodontics: a review. Oral Surgery Oral Medicine Oral Pathology Oral Radiology and Endodontics 2002;94:658-66.

2. Hülsmann $M$, Heckendorff $M$, LennonA'. Chelating agents in root canal treatment: mode of action and indications for their use-a review. International Endodontics Journal 2003;36:81030.

3. Ørstavik D, Haapasalo M. Disinfection by endodontic irrigants and dressings of experimentally infected dentinal tubules. Endodontics \& Dental Traumatology 1990;6:1429.

4. Mader $\mathrm{CL}$, Baumgartner JC, Peters DD. Scanning electron microscopic investigation of the smeared layer on root canal walls. Journal of Endodontics 1984;10:477-83.

5. Scelza MFZ, Antoniazzi JH, Scelza P. Efficacy of final irrigation- a scanning electron microscopic evaluation. J Endod 2000;26:355-8.

6. Torabinejad M, Khademi AA, Babagoli J, Cho Y, Johnson WB, Bozhilov K, Shabahang S. A new solution for the removal of the smear layer. Journal of Endodontics 2003;29:170-5.

7. Yamada RS, Armas A, Goldman M, Lin PS. A scanning electron microscopic comparison of a high volume final flush with several irrigating solutions. Part 3. Journal of Endodontics 1983;9:137-42.

8. Goldman M, Goldman LB, Cavaleri R, Bogis J, Lin $P S$. The efficacy of several irrigating solutions for endodontics: a scanning electron microscopic study. Part 2. Journal of Endodontics 1982;8:487-92.

9. Calt S, Serper A. Time dependent effects of EDTA on dentin structures. Journal of Endodontics 2002;28:17-9.

10. Niu W, Yoshioka T, Kobayashi C, et al. A scanning electron microscopic study of dentinal erosion by final irrigation with EDTA and $\mathrm{NaOCl}$ solutions. International Endodontics Journal 2002;35:934-9.

11. Torabinejad M, Cho Y, Khademi AA, Bakland LK, Shabahang $S$. The effect of various concentrations of sodium hypochlorite on the ability of MTAD to remove the smear layer. Journal of Endodontics 2003;29:233-9.

12. Garberoglio R, Becce C. Smear layer removal by root canal irrigants: a comparative scanning electron microscopic study. Oral Surgery Oral Medicine Oral Pathology Oral Radiology and Endodontics 1994;78:359-67.

13. Bystrom A, Sundqvist G. The antibacterial action of sodium hypochlorite and EDTA in 60 cases of endodontic therapy. International Endodontics Journal 1985; 18:35-40.

14. Baumgartner JC, Mader CL. A scanning electron microscopic evaluation of four root canal irrigation regimens. Journal of Endodontics 1987; 13:147-57. 
15. Wieczowski G, Davis EL, Joynt RB. Microleakage in various bonding agent composite resin systems. Oper Dent 1992;(Suppl 5):62-7.

16. Erickson RL. Surface interactions of dentin adhesive materials. Oper Dent 1992; (suppl 5):81-94.

17. Prabhu SG, Rahim N, Bhat KS, et al. Comparison of removal of endodontic smear layer using sodium hypochlorite, EDTA and different concentrations of maleic acid-a SEM study. Endodontology 2003;15:20-5.

18. Ballal NV, Kandian S, Mala K, Bhat KS, Acharya S. Comparison of the Efficacy of Maleic Acid and Ethylenediaminetetraacetic Acid in Smear Layer Removal from Instrumented Human Root Canal: A Scanning Electron Microscopic Study. J Endod 2009;35:1573-6.

19. Ahmad M, Pitt Ford TR, Crum LA. Ultrasonic debridement of root canals: an insight into the mechanisms involved. Journal of Endodontics 1987;13:93-101.

20. Baumgartner JC, Brown CM, Mader $\mathrm{CL}$, Peters DD, Shulman JD. A scanning electron microscopic evaluation of root canal debridemet using saline, sodium hypochlarite and citric acid. Journal of Endodontics 1984;10:525-31.

21. Grosman. LI. Endodontic Pratice, Lea and Febiger Co. Eight Edition. Philedelphia. 1974.

22. Mello I, Robazza CRC, Antoniazzi JH, Coil J. Influence of different volumes of EDTA for final rinse on smear layer removal. Oral Surgery Oral Medicine Oral Pathology Oral Radiology and Endodontics 2008;106:e40-3.

23. Hülsmann M, Rümmelin C, Schäfers F. Root canal cleanliness after preparation with different endodontic handpieces and hand instruments: a comparative SEM investigation. Journal of Endodontics 1997;23:301-6.

24. Serper A, Çalt S. The demineralizing effects of EDTA at different concentrations and $\mathrm{pH}$. Journal of Endodontics 2002;28:501-2.

25. O'Connell MS, Morgan LA, Beeler WJ, Baumgartner JC. A comparative study of smear layer removal using different salts of EDTA. Journal of Endodontics 2000;26:739-43.

26. Gettleman BH, Messer HH, El Deeb ME. Adhesion of sealer cements to dentin with and without the smear layer. Journal of Endodontics 1991;17:1520.

27. Goldberg F, Abramovich A. Analysis of the effect of EDTAC on the dentinal walls of the root canal. J Endod 1977;3:101-5.

28. Kuah HG, Lui JN, Tseng PSK, Chen NN. The Effect of EDTA with and without Ultrasonics on Removal of the Smear Layer. Journal of Endodontics 2009;35:393-6.

29. Jiang LM, Verhaagen $B$, Versluis $M$, van der Sluis LWM. Evaluation of a Sonic Device Designed to Activate Irrigant in the Root Canal. Journal of Endodontics 2010;36:143-6.

30. Mello I, Kammerer BA, Yoshimoto D, Macedo MCS, Antoniazzi JH (2010) Influence of Final Rinse Technique on Ability of Ethylenediaminetetraacetic Acid of Removing Smear Layer. J Endodon 36:512-4. 